Review Article

\title{
Pharmacological Properties and Health Benefits of Eugenol: A Comprehensive Review
}

\author{
Muhammad Farrukh Nisar $\mathbb{D}^{1,2}$ Mahnoor Khadim, ${ }^{2}$ Muhammad Rafiq $\mathbb{D}^{2},{ }^{2}$ Jinyin Chen $\left(\mathbb{D},{ }^{1,3}\right.$ \\ Yali Yang $(1),{ }^{4}$ and Chunpeng Craig Wan ${ }^{1}{ }^{1}$ \\ ${ }^{1}$ Jiangxi Key Laboratory for Postharvest Technology and Nondestructive Testing of Fruits \& Vegetables, College of Agronomy, \\ Jiangxi Agricultural University, Nanchang 330045, China \\ ${ }^{2}$ Department of Physiology and Biochemistry, Cholistan University of Veterinary and Animal Sciences (CUVAS), \\ Bahawalpur 63100, Pakistan \\ ${ }^{3}$ College of Materials and Chemical Engineering, Pingxiang University, Pingxiang 330075, China \\ ${ }^{4}$ Department of Pathology, Affiliated Hospital of Yunnan University/Second People's Hospital of Yunnan Province, \\ Kunming 650021, China
}

Correspondence should be addressed to Yali Yang; appleyangyali@126.com and Chunpeng Craig Wan; chunpengwan@jxau.edu.cn Received 12 May 2021; Accepted 17 July 2021; Published 4 August 2021

Academic Editor: Antonella Smeriglio

Copyright () 2021 Muhammad Farrukh Nisar et al. This is an open access article distributed under the Creative Commons Attribution License, which permits unrestricted use, distribution, and reproduction in any medium, provided the original work is properly cited.

\begin{abstract}
The biologically active phytochemicals are sourced from edible and medicinally important plants and are important molecules being used for the formulation of thousands of drugs. These phytochemicals have great benefits against many ailments particularly the inflammatory diseases or oxidative stress-mediated chronic diseases. Eugenol (EUG) is a versatile naturally occurring molecule as phenolic monoterpenoid and frequently found in essential oils in a wide range of plant species. EUG bears huge industrial applications particularly in pharmaceutics, dentistry, flavoring of foods, agriculture, and cosmeceutics. It is being focused recently due to its great potential in preventing several chronic conditions. The World Health Organization (WHO) has declared EUG as a nonmutant and generally recognized as safe (GRAS) molecule. The available literature about pharmacological activities of EUG shows remarkable anti-inflammatory, antioxidant, analgesic, and antimicrobial properties and has a significant effect on human health. The current manuscript summarizes the pharmacological characteristics of EUG and its potential health benefits.
\end{abstract}

\section{Introduction}

Eugenol (EUG) or 4-allyl-2-methoxyphenol is a phenylpropanoid having an allyl chain-substituted guaiacol (Figure 1). EUG, a naturally occurring compound, has been reported to be present in several plant families including Holy basil or tulsi leaves (Lamiaceae), Eugenia caryophyllata (clove), Zingiber officinale (ginger), bark and leaves of Cinnamomum verum (cinnamon), Curcuma longa (turmeric), and peppers (Solanaceae) [1], as well as various aromatic plants such as Cinnamomum verum (true cinnamon), Ocimum basilicum (basil), Myristica fragrans Houtt. (nutmeg), and Cinnamomum loureirii Nees. (Saigon cinnamon). The major natural sources of EUG are Eugenia caryophyllata (syn Syzygium aromaticum) which comprises $45-90 \%$ [2], and cinnamon has $20-50 \%$ of EUG, but the commercial level extraction of EUG is quite expensive with longer cultivation times, while ginger, tulsi, and bay can be used instead of cinnamon and clove as cheaper source [1].

EUG can be prepared synthetically by guaiacol allylation with allyl chloride or produced through biotransformation process that involves microorganisms like Escherichia coli, Corynebacterium sp., and Bacillus cereus [3]. The pharmacological properties of EUG are numerous including antimicrobial, anti-inflammatory, analgesic, neuroprotective, antidiabetic, and antitumor activities that make it a 


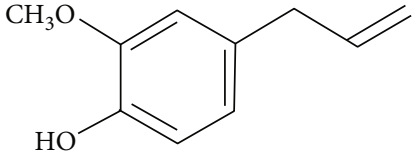

FIGURE 1: Structure of EUG.

versatile natural ingredient that helps in the prevention and cure of several disorders. The WHO declared EUG generally recognized as safe (GRAS) and a nonmutagenic substance. This naturally occurring molecule also has a large utilization in perfumery industry and food industry [4]. The antiseptic property made its use in mouthwashes as a disinfectant and also complexed with tooth fillers due to its pain relieving, antiseptic, and analgesic properties $[5,6]$. In agricultural practices, EUG have extensively been used as an insect attractant and even in pesticide production. At commercial scale, EUG proven itself a versatile compound mainly due to its structure, complex formation, and an excellent substrate for carrying out biotranformations $[7,8]$.

Medicinally important plant species are a good source of active and potent drugs bearing extensive pharmacological properties. There is a huge list of pharmacological activities and bioactivities of EUG along with industrial utilization. In spite of its strong antioxidant properties, EUG protects neuron cells and recues the chances of the oxidative stressoriented diseases as well as inflammatory diseases. Moreover, EUG is also used in local anesthesia to check the multiple pathological pains other than its wide utilization in dental clinics. Keeping in view the broad-spectrum utilization of EUG, the current review is aimed at highlighting and summarizing the recent advancements using EUG and exploring its pharmacological properties in a broader way. Moreover, this review will also discuss the roles of EUG in inflammatory and chronic diseases, in its antioxidant potential, and in neuroprotection.

\section{Pharmacological Properties of EUG}

The mechanism behind the therapeutic potential of EUG has been explained in huge literature. EUG is effective against a number of diseases such as reproductive disorders, nervous system disorders, blood glucose and cholesterol irregularities, microbial infections, tumorigenesis, hypertension, inflammations, and digestive complications [9]. Herein, the potential of EUG in combating severe illnesses and the mechanisms linked with health-promoting actions have been illustrated in detail [1].

2.1. Anticancer Activities. Cancer usually forms tumors by accumulation of cells and involves uncontrolled cell division. It is the second major cause of death worldwide, with a 6 million fatality rate annually $[10,11]$. Cellular aggregation can be a consequence of inflammation because of inappropriate performance of signaling pathways [11]. Chemotherapy is mostly employed to destroy cancer cells, but in addition to targeting the diseased cells, it also causes division of normal cells of hair follicles, bone marrow, etc. Therefore, chemopreventive natural agents, like EUG, are preferred for tumor therapy. These drugs, even at high dose, show no cytotoxic effect on healthy cells [12-14]. EUG has been declared nonmutagenic and noncarcinogenic by the US Food and Drug Administration (FDA) [15-17] (Figure 2).

Different studies on EUG demonstrated its strong potential in combating colon cancer, prostate cancer, skin tumors, and gastric cancers $[11,18-20]$. Therapeutic drugs undergo apoptosis as a therapy for cancer and many other diseases. Apoptosis is programmed cell death which causes plasma membrane shrinkage, blebbing, fragmentation in chromosomal DNA, production of membrane-bound small apoptotic bodies which are phagocytozed by nearby surrounding cells, and chromatin condensation $[10,21]$. Apoptosis is a vital function of the human body without which there is surely a great risk of many disorders like cancers, acquired immune deficiency syndrome (AIDS), etc. $[10,11,22]$.

Drug combination therapies are mostly used in combating cancer [23]. EUG shows a synergistic effect when used with some chemoinhibitory drug leading to a great reduction in drug toxicity on healthy cells [24]. In an in vitro study, use of little quantity of EUG in combination with gemcitabine potentiates the effects of the drug with no side effects on healthy cells $[1,11,25]$.

Breast cancer is ranked second among most common cancers in women, and it is classified as the fourth common cause of cancer-linked deaths worldwide [1]. Mammary epithelial cells in women are regulated by maintaining a balance among the process of their proliferation and apoptosis [26]. Disturbance in this balance leads to a rise in mammary epithelial cells finally causing breast cancer [26]. Vidhya and Devaraj [27] proved that breast cancer cells (MCF-7) experience strong antimutagenic activity of EUG. EUG is both time and dose dependent when suppressing proliferation of MCF7 cells $[17,27]$. Pisano and colleagues [28] also explained the antiproliferative action of EUG-associated biphenyl (S)-6,60dibromo-dehydrodieugenol, by initiating apoptosis.

Melanoma or malignant melanoma develops from melanocytes and is a sort of skin cancer [29]. Among all skin cancers, melanoma accounts for $4 \%$ only. However, it has a high mortality rate with over $80 \%$ of death toll from skin cancer [30]. The antiproliferative effect of EUG against melanocytes was studied by Pisano and coworkers [28]. EUG seize cell cycle and promote apoptosis. This effect of EUG has also been studied in a B16 xenograft model by Miyazawa and Hisama [31]. EUG acts by synthesis of ROS [17] which causes inhibition of DNA synthesis thus delaying tumor growth. $40 \%$ reduction was reported in tumor size by the action of EUG $[2,32]$. Another study was conducted by considering the anticancer activity of EUG on human melanoma cells (WM1205Lu). The results indicated apoptosis and cell cycle arrest at S-phase [2]. Ghosh and coworkers [33] examined EUG and isoeugenol for antimelanoma activity. They inferred that EUG, but not isoeugenol (isomer of EUG), showed anticancer activity against melanocytes [17].

Cervical cancer arises from the cervix. In 2002, cervical cancer resulted in 274,000 deaths [34]. More than $90 \%$ of cervical cancer cases are caused by human papillomavirus infection; most people who have had HPV infections, however, do not develop cervical cancer $[35,36]$. Experiments 


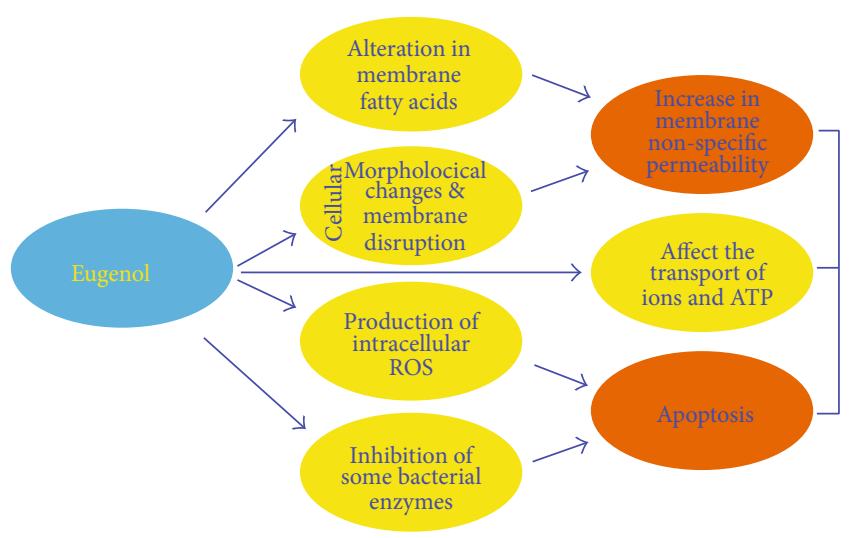

Figure 2: Cellular mechanism of EUG on cancer cells.

were conducted for studying the action of methyl EUG and cisplatin against cervical cancer cells (HeLa cells). The drugs were used separately and in combination. Methyl-EUG combined to cisplatin enhanced the anticancer effect by inducing apoptosis and destroying HeLa cells compared to the ample drug effects. Number of cells in G0/G1 phase, caspase-3 activity, and mitochondrial membrane potential loss were much enhanced in combination treatment in contrast to single drug exposure [23]. EUG showed a dose-dependent effect on HeLa cells [11].

2.2. Antioxidant Potential. Antioxidants protect body from the harms of free radicals by eliminating ROS or scavenging free radicals [37-39]. Unnecessary groups of free radicals are responsible for multiple human diseases like AIDS, cancer, and Parkinson's disease [1]. For a healthy body system, free radical production must be depressed [40]. Phenolic groups play a vital role in antioxidant action [41]. Availability of electrons for neutralizing free radicals is the basic principle of antioxidant action. Increasing the number of hydroxyl groups in phenol ring increases the capability to behave as hydrogen donor and prohibits oxidation [40]. Oxidative stress is an imbalance in antioxidant defense and ROS production $[42,43]$. Due to the disturbance in equilibrium between prooxidants and antioxidants, ROS production enhances leading oxidative stress which is concerned with inhibition of normal body functions [40]. Moreover, EUG has been reported to pose both prooxidant and antioxidant effects when applied to the cancer cells in a concentrationdependent fashion [44] (Figure 3). It was shown by electron spin resonance that the scavenging effect of EUG is due to the allyl group in its structure $[39,45]$. It hinders in lipid peroxidation leading to free radical destruction [46]. The EUG have great inhibitory effects on hexanal oxidation [47], copper-dependent LDL oxidation, iron-mediated lipid peroxidation [39], and nonenzymatic peroxidation in liver mitochondria [46] and hinder the onset of oxidative stressmediated diseases. EUG has an extraordinary reducing ability [48] and donates phenolic hydroxyl groups that can react with free radicals, diminishing oxidative stress thus a desirous antioxidant. Moreover, the antioxidant behaviour of EUG is greater than most of the known or standard antioxidants such as Trolox [40].

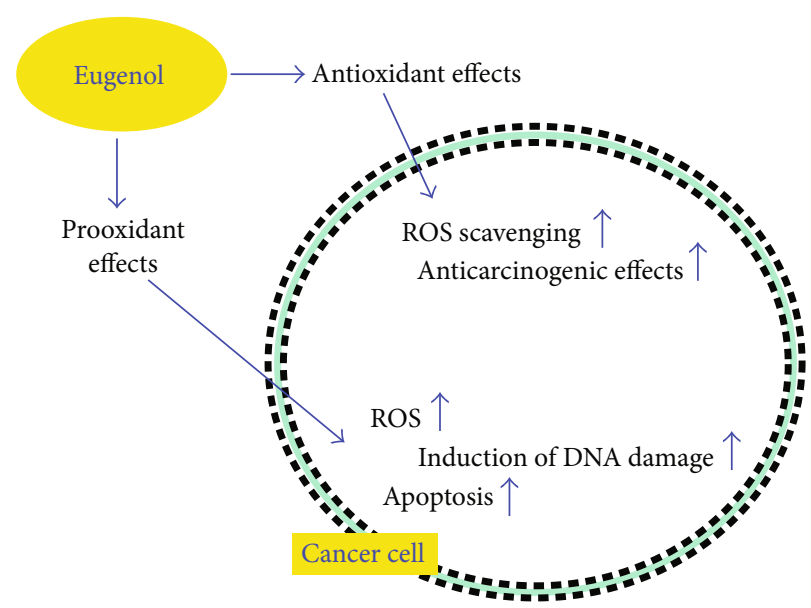

FIgUre 3: Prooxidant and antioxidant effects of EUG against cancer cells.

EUG shows dual properties, i.e., antioxidant as well as prooxidant actions, and later is the cause of cytotoxicity [49]. EUG behaves as an antioxidant at lower concentrations by minimizing ROS-mediated oxidative stress, but on the contrary, EUG at higher concentrations acts as a prooxidant to enhance the production of the ROS [16, 43, 50, 51]. Few studies showed that EUG eliminated free radicals through ABTS (2,2-azinobis (3-ethylbenzothiazoline-6-sulfonic acid) (76.9\%) and DPPH (89.9\%) in $L$-ascorbic acid [52]. Kaur and coworkers pretreated male Swiss albino mice with EUG and found a reduction in lipid peroxidation (LPO) and an inhibited depletion of antioxidant enzymes.

2.3. Cardiovascular Protection. Hyperlipidemia is the most common social issue in common people and causes cardiovascular diseases (CVDs) and lipid-related diseases [53]. CVDs and hyperlipidemic disorders are caused by less physical activity and high fatty acid intake [1]. High low-density lipoprotein cholesterol (LDL-c) leads to toxicity in vascular tissues and atherosclerosis/atherogenesis eventually causing diabetes; obesity; hypertension; inappropriate working of main body organs such as the kidneys, heart, and liver; and atherosclerosis [54].

CVD death and disease rate can be eradicated by less intake of lipids in the diet [55]. Reduced LDL-c concentrations also support in diminishing CVDs and improve atherosclerotic state $[56,57]$. ROS causes an increase or imbalance in oxidative stress homeostasis which results in enhancing a number of chronic diseases like coronary heart disease (CHD). Increased ROS production causes oxidative damage due to the disturbance in cellular antioxidant status [58].

Dyslipidemia is another example which is linked with oxidative stress and causes disregulation in working of cellular antioxidant stress response system [59]. Rice bran is widely used since decades because of its cholesterol-lowering, free radical scavenging, and antiatherogenic actions [60].

However, it is preferable to use natural and safer drugs in as minimum quantities as possible. EUG has a great antihypercholesterolemic and antiatherogenic potential. Venkadeswaran et al. [61] reported hypolipidemic effects of EUG in 
intraperitoneally injected Triton WR-1339 (300 mg/kg per B.W.) induced hyperlipidemic Wister male rats. EUG was more effective against high lipid and cholesterol content in comparison to a lipid-lowering drug (lovastatin). It caused a $55.88 \%$ reduction in total cholesterol; also, LDL-C (79.48\%) and triglycerides (64.30\%) were reduced.

EUG undergoes dose- and endothelium-dependent reversible vasodilator responses [20]. In hypersensitive rats, EUG showed a hyposensitive behaviour by inducing vascular relaxation [62]. The smooth muscle relaxant action of EUG is due to its blocking action on receptor-operated and voltagesensitive channels. Vascular relaxation is done via endothelial-generated nitric oxide (NO) [63]. The hypocholesterolemic action of EUG was well explained by a recent study using a hyperlipidemic zebra fish model, where EUG caused a great reduction in triglyceride (80\%) and cholesterol $(68 \%)$ levels in serum samples [64].

Hypercholesterolemia also causes an imbalance in the serum concentration of malondialdehyde (MDA, increased) and superoxide dismutase (SOD, decreased). This effect was studied by Munisa et al. [65], by the application of EUG against MDA and SOD in rats with high cholesterol level. They concluded that EUG regressed the concentrations to their normal ranges. Eugenol exerted negative inotropic effects in guinea pig heart muscles [66]. According to Choudhary et al. [67] EUG hinders isoproterenol-induced cardiac hypertrophy. The study was conducted on male Wister rats against EUG. They concluded that apoptosis, isoproterenol-induced oxidative stress, and calcineurin action in serum were suppressed [20].

2.4. Antidiabetic Activity. Hyperglycemia is a condition after which there is an outbreak of a degenerative disease called diabetes mellitus caused by abnormalities in glucose metabolism. Studies have shown that EUG is capable of curing several metabolic illnesses owing to its various pharmacological activities. EUG is a strong antidiabetic bioactive substance [1]. According to Anuj and Sanjay [39], EUG principally diminishes $\alpha$-glucosidases after which it intercepts the development of advanced glycation end (AGE) products [68]. In the presence of inhibitory $\alpha$-glycosidase compounds like EUG, dietetic complex carbohydrates do not undergo liberation of absorbable monosaccharides. The inhibitors prevent any drastic rise in meal-induced glucose level in blood by delaying the absorption of glucose into the bloodstream [69].

EUG enhances the activities of carbohydrate metabolism enzymes like glucose-6-phosphate dehydrogenase $(31.05 \%)$ and instance hexokinase $(62.25 \%)$. Studies show that a diminishing effect has also been observed by the application of EUG on creatine kinase $(38.57 \%)$, glucose-6-phosphatase $(24.45 \%)$, blood urea nitrogen $(34.01 \%)$, and fructose-1,6bisphosphatase [70].

Tahir et al. [68] demonstrated the antidiabetic potential of S. aromaticum and Cuminum cyminum (C. cyminum) following the $\alpha$-amylase enzyme assay method. Starch is converted to simple sugars by $\alpha$-amylase which is a human enzyme and is involved in causing diabetes. The rate at which glucose absorbs into the blood stream can be reduced by the application of inhibition of $\alpha$-amylase enzyme. The enzyme retards the digestion of carbohydrates ultimately causing a decrease in blood glucose level. The antidiabetic activity is dose dependent. S. aromaticum depicted more antidiabetic potential than C. cyminum, as $S$. aromaticum is chiefly composed of EUG (18.7\%) while the main constituent of C. cyminum is composed of á-pinene (18.8\%) [68]; the antidiabetic potential of S. aromaticum was found to be $95.30 \%$ which is greater than $83.09 \%$ of C. cyminum. These results proved that EUG has a great antidiabetic potential compared with many related essential oils [68].

Srinivasan et al. experimented male diabetic rats by inducing streptozotocin drug ( $40 \mathrm{mg} / \mathrm{kg}$ per B.W.) in them. The activity of major enzymes taking part in the glucose metabolism was studied to examine efficacy of EUG. In contrast, only a $10 \mathrm{mg} / \mathrm{kg}$ per B.W. dosage of EUG greatly enhanced hepatic glycogen and insulin in plasma (46.15\%) samples with a reduction in glycosylated haemoglobin (25.70\%) and blood glucose (70\%) [70].

2.5. Antiparasite Activity. The majority of human parasites are a key cause of increased mortalities compared with rest of the issues excluding tuberculosis (TB) and AIDS [71]. Certain drastic effects of EUG have been reported on morphology and growth of various parasites like Trypanosoma cruzi, Giardia lamblia, and Leishmania donovani [72]. Schistosomiasis is a parasitic helminthic infection in about 78 different countries caused by parasitic flatworms or blood fluke schistosomes (S. haematobium, S. mansoni, S. japonicum, and S. mansoni) and also familiar as bilharzia or snail fever which is somewhat a neglected tropical disease [72-75]. Schistosomiasis gets settled in intestinal venules to affect the gut, urinary tract, and liver which results in retardation of growth, anemia, enlarged liver, and even liver fibrosis [72]. EUG can be used as an antiparasitic agent with least side effects than other chemotherapeutics in curing various parasitic diseases, and overdose of EUG shows antileishmanial, antimalarial, and antihelmintic potentials. In an in vivo study using mouse models, the drug-resistant parasite Schistosoma mansoni showed a great reduction (19.2\%) following a synergistic effect of EUG in combination with conventional drugs [72]. Moreover, it is further noticed that EUG had no effect on egg development of worms owing to the fact that the oogram patterns of the treated group of mice and nontreated group of mice were similar, but the egg density in the walls of the intestines of mice was greatly reduced by the application of EUG [76]. Protozoans like Leishmania are the major cause of leishmaniasis in humans, and the pathogens are being transferred through the bite of infected phlebotomine female sandflies [77]. Leishmaniasis can be mucosal, visceral, or cutaneous and if it gets combined with human immunodeficiency virus may cause a serious condition [39]. Most of the pathogenic parasites have developed resistance with course of time against standard drugs; thus, use of natural phytochemicals like EUG is preferred [78]. Following a 60 min treatment of EUG in combination with essential oils showed absolute (100\%) destruction of L. amazonensis parasites [79] primarily by the increased production of EUG-mediated nitric oxide (NO) which is an antileishmanial oxidant involved in triggering the killing of leishmania species $[39,79]$. 
2.6. Antibacterial and Antiviral Activities. EUG have been well known for its antimicrobial potential and uses. Majority of food-borne diseases are attributed to the microorganisms and are an escalating health issue of global public. About one-third of the population in industrial countries are facing food-borne diseases issues. In the US, 31 notable pathogens give rise to approximately 9.4 million cases of food-borne diseases per annum [80]. EUG can be bactericidal (bacterial killing) or bacteriostatic (inhibiting bacterial growth) depending on the MIC (minimum inhibitory concentration) and MBC (minimum bactericidal concentration) [81] and have antivirus and antifungal effects at the same time. EUG shows dynamic antibacterial ability against a variety of strains of gram-negative (Pseudomonas aeruginosa, Salmonella choleraesuis, Yersinia enterocolitica, Helicobacter pylori, and E. coli) and gram-positive (Streptococcus pneumonia, S. aureus, Enterococcus faecalis, and Streptococcus pyogenes) bacterial strains. EUG has proven to be active against several bacterial enzymes like histidine, amylase, ATPase, and proteases [82, 83]. The presence of a free hydroxyl group in the EUG molecule is the main cause of its great antimicrobial activity [84]. EUG extracted from clove oil adversely disrupts the cell wall and cell membrane of bacteria, and this lysis leads to an enhanced fluidity and permeability of cell membrane $[85,86]$ followed by membrane expansion, leakage of intracellular fluids accompanied by proteins and lipids release, respiration inhibition, alteration of ion transport patterns of bacteria [81, 83], and disturbance of membrane-embedded proteins, consequently leading to the cell death [87]. Catherine et al. [88] tested the antibacterial potential of EUG in combating (MIC 0.15-0.25\%) foodborne bacteria E. coli, Yersinia enterocolitica, S. aureus, and Bacillus cereus and proven that gram-negative bacteria are more resistant than its counterpart gram positive [88]. The combination therapy by making fusion of plants is quite effective for the treatment of critical bacterial infections $[2,89]$. The antibacterial activity of EUG was amplified when combined with vancomycin, where the half of the bacterial membranes are damaged due to EUG and hence facilitate the vancomycin penetration into the membrane $[2,90]$. The combined effect of EUG with gentamicin or ampicillin resulted in a much higher killing rate in an hour time than EUG applied alone [2, 91].

Herpes simplex virus (HSV) infects persons 50 years and is a frequent sexually transmitted infection [92]. The medicinal plants are a rich source of EUG that retards the replication of HSV by neutralizing and inactivating the viral infections $[93,94]$. The mechanism behind antiviral actions of EUG is the upregulation of the expression of HSV-1glycoprotein B that checks HSV replication [95], while some studies confirmed that EUG inhibits the replication of the HSV-1 and HSV-2 DNA molecules, as well as damages the outer envelope of newly synthesized virions [96-98]. The benefits of using combination chemotherapy includes enhanced antiviral activity, reduced dosage of toxic substances, and lessened development of drug resistance [99]. In in vivo study involving mouse models, Eugenia caryophyllus extracts rich in EUG which were applied in combination with acyclovir (ACV) showed an anti-HSV-1 potential in the brain and skins of mice $[97,100]$. In this ACV-EUG therapy, ACV specifically targets DNA molecules and inhibits the replication process [101]. In HSV-1-infected mice, EUG therapy delayed the production of herpetic keratitis in the cornea [39] which shows a close association of EUG on the ocular herpetic infections [93]. EUG disintegrates the lipidic envelope of the HSV virus and also induces glutathione Stransferase (GST) expression in liver cells of rats, eventually blocking replication process.

2.7. Antifungal Activity. EUG has shown lethal effects on the growth of different strains of fungi such as Fusarium graminearum, F. moniliforme, Tricophyton rubrum, Penicillium citrinum, Candida tropicalis, C. krusei, and Aspergillus ochraceus. EUG either causes cell cycle arrest or affects fungal cell membrane integrity by disruption [102]. Owing to the lipophilic nature of the EUG, it gets accumulated in the phospholipid bilayer of fungal cells, altering the functions of vital membrane-bounded enzymes, affecting permeability, fluidity of membrane, and envelope morphogenesis [103, 104]. Another recent study claimed that by the addition of the methyl radical in the EUG, it may amplify its antifungal potent to many folds [105]. Combination therapies are often employed for better results. A synergistic interaction of EUG or isoeugenol with that of fluconazole (EUG/isoeugenol-fluconazole/amphotericin B) was applied against multidrugresistant strain C. albicans and found extraordinary effectiveness [2]. Furthermore, EUG have been reported to affect the morphology of the fungal strains especially the hyphae of $B$. cinerea which showed much irregular structural features such as broken or shriveled hyphae, large vesicles, and leaked intracellular contents. In addition to morphological alterations, EUG induces the accumulation of ROS especially hydrogen peroxide $\left(\mathrm{H}_{2} \mathrm{O}_{2}\right)$ in the fungal cells to generate oxidative stress which ultimately bursts the fungal hyphae [103].

2.8. Anti-Inflammatory Activity. Inflammation is called as the body's adaptive immunity response, triggered by noxious stimuli, tissue infection, and injury [106]. It can be chronic or acute [107], and anti-inflammatory drugs used nowadays have adverse effects [108]. EUG, with no side effects, has a tremendous anti-inflammatory potential (Figure 4). EUG can be used in the protection of damage resulting from oxidative stress [52]. The ROS-mediated oxidative stress results in cellular damage and LPO [109]. Saraiva et al. [108] showed that oxidative stress and inflammation are interlinked mechanisms. In a study, male Swiss albino mice when treated with EUG have undergone reduced LOP and in expression levels of inflammatory markers, viz., COX-2, iNOS, and cytokine tumor necrosis factor $\alpha$ (TNF- $\alpha$ ), and antioxidant enzymes [19]. Generally, EUG pretreatment reduces inflammations (as a result of the action of LPS on lungs) in cells.

Biswas et al. [110] studied pulmonary inflammation in mouse and action of EUG as an antiagent. It was concluded that EUG causes significant reduction in the much higher levels of neutrophils and TNF- $\alpha$ and also maintained the proinflammatory mediators. Magalhães et al. [111] investigated anti-inflammatory properties of EUG in lipopolysaccharideinduced lung injury for $6 \mathrm{~h}$ in vivo. A decrease of 


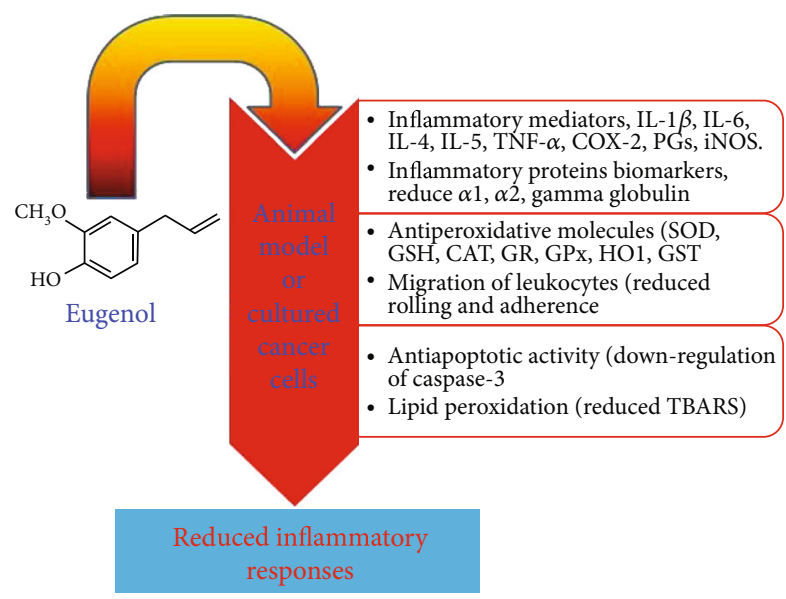

FIGURE 4: Effect of EUG on controlling the inflammations.

proinflammatory cytokines like TNF- $\alpha$, NF- $\kappa$ B-mediated signalizing pathway, and macrophage infiltration were reported, eventually leading to an improvement in the function and structure of the lungs due to a decrease in inflammation [52]. EUG inhibits TNF- $\alpha$ and cyclooxygenase-2 (COX-2) expression [112]. Its anti-inflammatory action is attributed to macrophage chemotaxis and prostaglandin synthesis. In a study, it was revealed that EUG suppresses the activation of NF- $\kappa$ B-stimulating macrophages mainly due to TNF- $\alpha$ and COX-2 actions. COX-2 effect is enhanced by lipopolysaccharides (LPS) [113]. The expression of antioxidant enzymes like glutathione peroxidase (GPX) and superoxide dismutase (SOD) is significantly enhanced by EUG (Figure 4).

2.9. Antipyretic Activity. The antipyretic efficacy of EUG was examined by Feng and coworkers [114], where they found an antipyretic effect of EUG against a well-known antipyretic acetaminophen in rabbits made febrile by IL- $1 \beta$. It shows a significant antifever action than acetaminophen when induced intragastrically, centrally, and intravenously. When given intragastrically, EUG in addition to treating fever, induces slight hypothermia unlike acetaminophen. Acetaminophen reduced fever by $68 \%$ at a dose of $1.3 \mathrm{mM} / \mathrm{kg}$ while EUG reduced $68 \%$ fever at a much less dosage. When given peripherally, it shows marked results in inhibiting fever. When given intravenously, respiration of rabbits and vasodilation in ears were increased. Increased respiration depicts that EUG have a positive action on the central nervous system (CNS). If prostaglandins and sodium archidonate mediate fever in the CNS, acetaminophen and EUG can inhibit fever by retardation of prostaglandin $\mathrm{R}$ and sodium archidonate synthesis. Both these drugs show the same antipyretic mechanism but EUG shows more potent behaviour as compared to acetaminophen [115].

2.10. Antinociceptive Activity (Analgesic). EUG is significantly efficient in relieving pain by reducing the responses that are linked with pain. It suppresses several responses to histamine, norepinephrine, and stimulation of periarterial sympathetic nerves [116] and inhibits prostaglandin synthesis [117]. It is mostly used as a dental analgesic and antiseptic agent [118]. Its analgesic effect is linked to suppress $\mathrm{Na}^{+}, \mathrm{K}^{+}$, and $\mathrm{Ca}^{2+}$ voltage-dependent channels $[119,120]$. The highvoltage-activated $\mathrm{Ca}^{2+}$ channel (HVACC) inhibition by EUG plays an important role in pain-relieving effect. It inhibited HVACC currents in both capsaicin-insensitive and capsaicin-sensitive dental primary afferent neurons [121]. TRPV-1 receptors are involved in pain stimulation. A study revealed that EUG inhibited TRPV-1 by suppressing voltage-activated $\mathrm{Na}^{+}$and $\mathrm{Ca}^{2+}$ channels $[2,122]$.

EUG is an antagonist towards NMDA (N-methyl-Daspartate) and gamma-aminobutyric acid (GABA); both are involved in pain transmission $[123,124]$. It inhibits $\mathrm{Ca}^{2+}$. dependent release of neurotransmitters and also retards interleukin (IL-) $1 \beta$ and PGE2 synthesis [39]. Park et al. [125] studied the analgesic action of EUG in the orofacial part and reported its inhibitory action on VGSCs in trigeminal ganglion (TG) neurons.

Ferland et al. [126] performed experiments on a monoiodoacetate-induced rat model of osteoarthritis to find the effects of EUG. The affected limb showed marked improvement when administered with EUG for two days after osteoarthritis induction. Also, calcitonin gene-related peptide (CGRP) which is associated with spinal cord pain was reduced. The antinociceptive potential of EUG was investigated by Daniel et al. [127] in mice using acetic-acidinduced abdominal writhing process. EUG showed a significant result in decreasing the pain. The effect of EUG in several experimental pain models using mice was studied such as acetic acid-mediated abdominal constrictions, formalin-mediated hyperalgesia, and thermal pains, and $92.73 \%, 70.33 \%$, and mild inhibitions in pain were found, respectively [128].

2.11. Effects on the Central Nervous System (CNS), Neuroprotection, and Antistress Activity. EUG in addition to acting on the periphery also performs actions in the central nervous system (Figure 5). The hydrophobic property of EUG makes it efficient in penetrating the blood-brain barrier for its entry into the brain and performs its action in vivo [129]. EUG guards neuronal cells against N-methyl-D-aspartate- (NDMA-) induced oxidative and excitotoxic injury [39]. EUG shows a neuroprotective potential on hippocampal tissues owing to its power reduce brain-derived neurotrophic factor (BDNF), and retardation of amyloid- $\beta$ peptide $(\mathrm{A}-\beta)$ induced cell death through the abnormal blockage of $\mathrm{Ca}^{2+}$ (resulted from A- $\beta$ ) [130]. Its ability to restrict antioxidant and excitotoxicity effects also contributes in neuroprotection. In cell models, EUG improves actions of few glutathione-related proteins and shields essential neuronal cells from oxidative and excitotoxic effects [131]. The inhibitory action of EUG has been reported on 5-lipoxygenase, in addition to an improved action in response to excitotoxic and ROS-injured neuron cells [132].

Depression, a neurodegenerative disorder, causes common psychological disorders, and $10-20 \%$ of the general population suffer through it. EUG showed a marked effect as an antidepressant in force swimming test (FST) and tail suspension test (TST) comparable to an antistress drug imipramine [39]. The mechanism of action of these two 


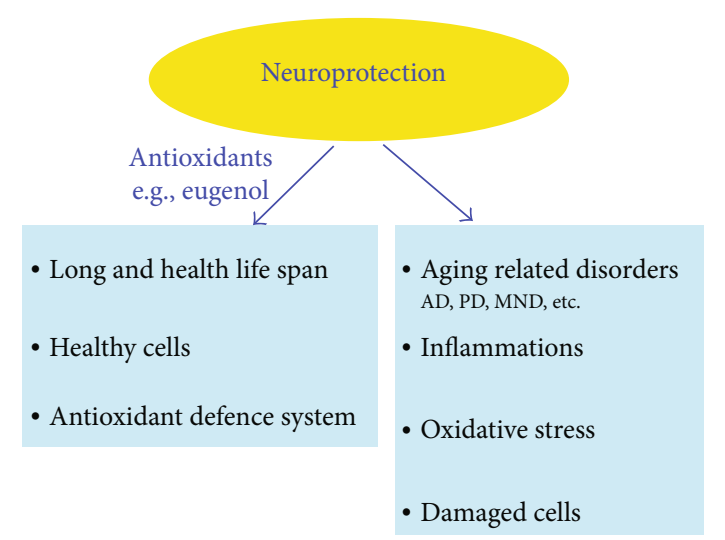

Figure 5: The role of EUG in neuroprotection and neurodegenerative diseases in the CNS involves various mechanisms including oxidative stress, damaged/unrepaired cells, and inflammations.

drugs is different. Real-time PCR (RT-PCR) showed that metallothionein-III (MT-III) was found to be linked with the antidepressive effect of EUG quite different from imipramine. This forms the basis of an alternative treatment if the patients develop resistance to typical drugs. EUG exhibits antiepileptic potential. It performs its action by blocking long-term potentiating and synaptic transmission in neurons [133]. Sen et al. [134] reported the antistress activity of EUG. EUG acts at a central level to pose neuroprotective effects against ischemia, excitotoxicity, and amyloid- $\beta$ peptide. In experimental diabetes, EUG improves vascular and neuronal complications and suppresses the transmission of action potential in sciatic nerves [39]. It also elongates the kallikrein- and bradykinin-induced tranquilization [135]. EUG is a good medicine for Alzheimer's disease (AD) and depression. Moreover, the expression of the BDNF gene in the hippocampus is also controlled by EUG. It also retards monoamine oxidase A (MAO-A) and sometimes reverts back monoamines that are reduced in the brains of depressed patients [129]. EUG has been proved useful against stressinduced irritable bowel syndrome (IBS) [136].

Regulation of release of neurotransmitters by EUG eventually moderates different brain functions. Rats with $4 \mathrm{~h}$ restraint stress model were studied by Garabadu et al. [137], and antistress potential of EUG was observed. It was concluded that EUG administration enhanced ulcer index and corticosterone and norepinephrine levels. EUG also brought alteration in serotonin (5-HT) levels in almost all parts of the brain. This study elaborates the antistress actions of EUG that are ascribed with the modulation of hypothalamic pituitary adrenal (HPA) as well as brain monoaminergic systems (BMS). Under stress situations, sympathoadrenal (SA) and BMS and HPA regulate several physiological and psychological responses [137].

The neuroprotective efficacy of EUG and isoeugenol in response to acrylamide-mediated neuropathy in male albino rats was studied by Prasad [138], where it was found that both the drugs increase the behavioral index gait level and reduce the oxidative stress-linked markers like $\mathrm{NO}$ and ROS. Dopamine, acetylcholinesterase activity, and cytosolic
$\mathrm{Ca}^{2+}$ levels are also diminished in the brain. It is further demonstrated that EUG and isoeugenol potentially restrict acrylamide-mediated neuropathic condition in rats and due to this factor, they can be directly used through diet to soothe different neuropathic conditions in humans [138].

2.12. Neurodegenerative Disorders. Neurological disorders include a number of conditions whose inception results from subsequent degradation of normal function and morphology of neurons, mainly in the CNS [139]. Globally, 20 million people are suffering from only these three disorders [140]. Neural disorders have been ranked by the WHO as the second (12\%) most reason of mortalities worldwide. Disorders linked with neurodegeneration include Parkinson's disease (PD), AD, prion diseases, ischemia, hydrocephalus, Huntington's disease, head and brain malformations, and spongiform encephalopathies [141]. Among the neurodegenerative diseases, $\mathrm{AD}, \mathrm{PD}$, and motor neuron disease (MND) are most common. Natural agents are frequently employed for the treatment of various neurological disorders (Figure 5). It was demonstrated by ancient Chinese researchers that a number of herbs used in treatment of AD consists of Rhizoma acori graminei extracts enriched with EUG [39].

The neurodegenerative disorder AD is described characterized by the loss of neurotransmitters and neurons and is accompanied by depression and PD [129]. Neuronal degeneration in the CNS involves various mechanisms including apoptosis, protein accumulation, ageing, and oxidative stress, which are contributing to neurodegenerative disorders (Figure 5). The most common among these is the aggregation of misfolded proteins, which display amyloid characteristic (formation of $\beta$-pleated sheets), calling this group of illness called as brain amyloidosis [140].

2.13. The Enhancement in Skin Permeation. The stratum corneum of the skin is composed in a way to control the passive movement of substances across the skin. A common way for enhancing drug permeation through the skin is the transdermal drug delivery. Use of small electric charge for the transport of a substance (drug) across the skin is called iontophoresis and is used to compensate for impermeability of the skin, in addition to chemical permeation enhancers like essential oils [142, 143]. Anuj and Sanjay [39] investigated the permeation enhancer ability of EUG in the absorption of tamoxifen. EUG increased the permeability of tamoxifen across porcine epidermis as compared to $50 \%$ ethanol. Furthermore, EUG and acetyl-eugenol were also seen for transdermal delivery of ibuprofen in rabbits and noted to enhance permeation with great 7.3 enhancement ratio [144].

2.14. Toxicity. EUG toxic behaviour has been studied in multiple in vivo studies. However, little or no information is available in humans [39]. EUG toxic behaviour depends mainly on its concentration; i.e., its effects are dose dependent [52]. The prooxidant effect of EUG leads to its toxicity [43], and Medeiros et al., [145] reported that toxicity of EUG is attributed to protein inactivation due to the binding of EUG at the lysine residues. Cytotoxicity of EUG is possibly 
due to its metabolic reactions. The reactive metabolites then react further with DNA, forming adducts that can destroy nuclear genetic material. EUG has been proved as a contact allergen in dentistry [39] and makes its entry into the bloodstream by penetrating dental pulp tissue, causing chromosomal aberrations (CAs) in dental pulp cells in humans [146].

2.15. Wide Application of EUG in Dentistry. EUG, due to its antioxidant, anti-inflammatory, anesthetic, and analgesic potentials, is used extensively in dentistry at low dosage. In dental emergencies, it is used as an anodyne [147]. It is used as a cementing material in dentistry [118], and the first type of EUG cement was developed earlier back in 1933 which comprises of EUG liquid and $\mathrm{ZnO}$ powder, forming a paste. In tooth preparation, EUG owing to its sedative potential provides soothing action for assisting in pulp relaxation after contusion [148]. ZnO EUG cement is presently being used in dentistry in root canal sealing; temporary fillings and indirect pulp capping are the widespread uses of $\mathrm{ZnO}+\mathrm{EUG}$ cement (ZOE) [147]. Park et al. [125] studied the action of EUG on pain behaviors in the orofacial region and the retardation of voltage-gated sodium channels (VGSCs) in trigeminal ganglion (TG) neuron cells.

2.16. Miscellaneous. At high concentrations, EUG has also been reported to provide anesthetic effects during a pharmacokinetic study using male Sprague-Dawley rats [149]. Tajuddin et al. [150] observed an improved sexual behaviour of male Swiss mice after EUG administration. It also shows antiulcerogenic effects. Furthermore, two ulcerogenic agents induced gastric ulcer which was diminished by treatment with EUG. The gravity of lesions was also decreased by EUG [151]. The antiulcer action of EUG is brought about by its free radical scavenging activity, less acid-pepsin secretion, inhibition of a great rise in NO level, and opening of ATP-sensitive potassium (KATP) channels [53]. In vivo examination finds that diarrhea caused by castor oil was reduced by EUG. Also, the intestinal aggregation of fluid induced by PGE2, the rate of intestinal transit, and the tone of isolated gut muscle and myometrium were also suppressed [152]. Karmakar et al. [153] reported an ovariectomised (OVX) model of rats induced with osteoporosis against EUG and its derivatives. The drug showed a marked effect on the efficiency of bone preservation.

\section{Conclusion}

The current review summarized the potential health benefits and effectiveness of EUG as a therapeutic agent which can be used in medicines and food for the treatment of inflammatory and oxidative stress-oriented disorders. The antioxidant, anti-inflammatory, antipyretic, analgesic, antiparasite, and antimicrobial properties of EUG are well described. It has a great role in neuroprotection, enhances skin permeability, relieves pains, and has a role in temporary dental filler formation ( $\mathrm{ZnO}+\mathrm{EUG})$. EUG has no known toxicity in smaller quantities, but at higher concentrations, it behaves as prooxidant; hence, a strong anticancer activity is shown by this molecule. Furthermore, diverse applications of EUG such as its pharmacological importance in regulating blood cholesterol and lipid levels are also discussed. Future studies involving a specified dose range of EUG to cure different ailments are recommended to highlight this molecule for the development of drugs.

\section{Abbreviations}

5-HT: 5-Hydroxytryptamine (serotonin)

ABTS: 2,2-Azinobis (3-ethylbenzothiazoline-6-sulfonic acid)

ACV: Acyclovir

AD: $\quad$ Alzheimer's disease

AGE: Advanced glycation end

AIDS: Acquired immune deficiency syndrome

A- $\beta$ : $\quad$ Amyloid- $\beta$ peptide

BDN: $\quad$ Brain-derived neurotrophic factor

BMS: Brain monoaminergic systems

CAs: Chromosomal aberrations

CGRP: Calcitonin gene-related peptide

CHD: $\quad$ Coronary heart disease

CNS: Central nervous system

COX-2: Cyclooxygenase-2

CVD: Cardiovascular diseases

DNA: Deoxyribonucleic acid

DPPH: 2,2-Diphenyl-1-picrylhydrazyl

EUG: Eugenol

FAO: $\quad$ Food and Agricultural Organization (of United Nations)

FDA: $\quad$ Food and Drug Administration

FST: $\quad$ Force swimming test

GABA: Gamma-aminobutyric acid

GPX: Glutathione peroxidase

GRAS: Generally recognized as safe

GST: Glutathione S-transferase

$\mathrm{H}_{2} \mathrm{O}_{2}$ : Hydrogen peroxide

HPA: Hypothalamic pituitary adrenal

HSV: $\quad$ Herpes simplex virus

HVACC: High-voltage-activated $\mathrm{Ca}^{2+}$ channel

IL-1 $\beta$ : Interleukin-1 $\beta$

IL-6: Interleukin-6

iNOS: Inducible nitric oxide synthase

KATP: ATP-sensitive potassium channels

LDL: Low-density lipoprotein

LDL-c: Low-density lipoprotein cholesterol

LPO: $\quad$ Lipid peroxidation

LPS: Lipopolysaccharides

MAO-A: Monoamine oxidase a

MBC: $\quad$ Minimum bactericidal concentration

MCF-7: Michigan Cancer Foundation-7

MDA: Malondialdehyde

MIC: Minimum inhibitory concentration

MND: $\quad$ Motor neuron disease

MT-III: Metallothionein-III

NF- $\kappa$ B: Nuclear factor kappa light chain enhancer of activated beta cells

NO: $\quad$ Nitric oxide

OVX: Ovariectomised 


$\begin{array}{ll}\text { PCR: } & \text { Polymerase chain reaction } \\ \text { PD: } & \text { Parkinson's disease } \\ \text { PGE2: } & \text { Prostaglandin } \mathrm{E}_{2} \\ \text { ROS: } & \text { Reactive oxygen species } \\ \text { SA: } & \text { Sympathoadrenal } \\ \text { SOD: } & \text { Superoxide dismutase } \\ \text { TB: } & \text { Tuberculosis } \\ \text { TG: } & \text { Trigeminal ganglion } \\ \text { TNF- } \alpha: & \text { Tumor necrosis factor } \alpha \\ \text { TRPV-1: } & \text { Transient receptor potential vanilloid-1 } \\ \text { TST: } & \text { Tail suspension test } \\ \text { VGSCs: } & \text { Voltage-gated sodium channels } \\ \text { WHO: } & \text { World Health Organization } \\ \text { ZnO: } & \text { Zinc oxide } \\ \text { ZOE: } & \text { Zinc-oxide eugenol. }\end{array}$

\section{Data Availability}

All of the data used to elaborate and explain the findings herein are already given within the draft.

\section{Conflicts of Interest}

None of the authors have declared the conflict of interest for the submission and publication of this article in this journal.

\section{References}

[1] A. A. Khalil, U. . Rahman, M. R. Khan, A. Sahar, T. Mehmood, and M. Khan, "Essential oil eugenol: sources, extraction techniques and nutraceutical perspectives," RSC Advances, vol. 7, no. 52, pp. 32669-32681, 2017.

[2] G. P. Kamatou, I. Vermaak, and A. M. Viljoen, "Eugenol-from the remote Maluku Islands to the international market place: a review of a remarkable and versatile molecule," Molecules, vol. 17, no. 6, pp. 6953-6981, 2012.

[3] M. R. Abrahão, G. Molina, and G. M. Pastore, "Endophytes: recent developments in biotechnology and the potential for flavor production," Food Research International, vol. 52, no. 1, pp. 367-372, 2013.

[4] A. Sartoratto, A. L. M. Machado, C. Delarmelina, G. M. Figueira, M. C. T. Duarte, and V. L. G. Rehder, "Composition and antimicrobial activity of essential oils from aromatic plants used in Brazil," Brazilian Journal of Microbiology, vol. 35, no. 4, pp. 275-280, 2004.

[5] B. K. Jadhav, K. R. Khandelwal, A. R. Ketkar, and S. S. Pisal, "Formulation and evaluation of mucoadhesive tablets containing eugenol for the treatment of periodontal diseases," Drug Development and Industrial Pharmacy, vol. 30, no. 2, pp. 195-203, 2004.

[6] N. Sarrami, M. N. Pemberton, M. H. Thornhill, and E. D. Theaker, "Adverse reactions associated with the use of eugenol in dentistry," British Dental Journal, vol. 193, no. 5, pp. 257-259, 2002.

[7] S. Ouk, S. Thiébaud, E. Borredon, and P. le Gars, "Dimethyl carbonate and phenols to alkyl aryl ethers via clean synthesis," Green Chemistry, vol. 4, no. 5, pp. 431-435, 2002.

[8] T. S. Kaufman, "The multiple faces of eugenol. A versatile starting material and building block for organic and bioorganic synthesis and a convenient precursor toward bio- based fine chemicals," Journal of the Brazilian Chemical Society, vol. 26, no. 6, pp. 1055-1085, 2015.

[9] F. M. Rauscher, R. A. Sanders, and J. B. Watkins III, "Effects of isoeugenol on oxidative stress pathways in normal and streptozotocin-induced diabetic rats," Journal of Biochemical and Molecular Toxicology, vol. 15, no. 3, pp. 159-164, 2001.

[10] R. Yu, S. Mandlekar, K. J. Harvey, D. S. Ucker, and A. N. Kong, "Chemopreventive isothiocyanates induce apoptosis and caspase-3-like protease activity," Cancer Research, vol. 58, no. 3, pp. 402-408, 1998.

[11] A. Hussain, K. Brahmbhatt, A. Priyani, M. Ahmed, T. A. Rizvi, and C. Sharma, "Eugenol enhances the chemotherapeutic potential of gemcitabine and induces anticarcinogenic and anti-inflammatory activity in human cervical cancer cells," Cancer Biotherapy and Radiopharmaceuticals, vol. 26, no. 5, pp. 519-527, 2011.

[12] B. B. Aggarwal and S. Shishodia, "Molecular targets of dietary agents for prevention and therapy of cancer," Biochemical Pharmacology, vol. 71, no. 10, pp. 1397-1421, 2006.

[13] S. Lev-Ari, A. Vexler, A. Starr et al., "Curcumin augments gemcitabine cytotoxic effect on pancreatic adenocarcinoma cell lines," Cancer Investigation, vol. 25, no. 6, pp. 411-418, 2007.

[14] J. Park, V. Ayyappan, E. K. Bae et al., "Curcumin in combination with bortezomib synergistically induced apoptosis in human multiple myeloma U266 cells," Molecular Oncology, vol. 2, no. 4, pp. 317-326, 2008.

[15] D. Opdyke, "Monographs on fragrance raw materials: hydroxycitronellal dimethylacetal," Food and Cosmetics Toxicology, vol. 13, no. 5, pp. 548-549, 1975.

[16] S. K. Jaganathan and E. Supriyanto, "Antiproliferative and molecular mechanism of eugenol-induced apoptosis in cancer cells," Molecules, vol. 17, no. 6, pp. 6290-6304, 2012.

[17] R. S. Bendre and J. Rajput, "Outlooks on medicinal properties of eugenol and its synthetic derivatives," Natural Products Chemistry \& Research, vol. 4, no. 212, p. 2, 2016.

[18] K. B. Harikumar, A. B. Kunnumakkara, G. Sethi et al., "Resveratrol, a multitargeted agent, can enhance antitumor activity of gemcitabine in vitro and in orthotopic mouse model of human pancreatic cancer," International Journal of Cancer, vol. 127, no. 2, pp. 257-268, 2010.

[19] G. Kaur, M. Athar, and M. S. Alam, "Eugenol precludes cutaneous chemical carcinogenesis in mouse by preventing oxidative stress and inflammation and by inducing apoptosis," Molecular Carcinogenesis: Published in cooperation with the University of Texas MD Anderson Cancer Center, vol. 49, no. 3, pp. 290-301, 2010.

[20] K. Pramod, S. H. Ansari, and J. Ali, "Eugenol: a natural compound with versatile pharmacological actions," Natural product communications, vol. 5, no. 12, p. 1934578X1000501, 2010.

[21] A. Fleischer, A. Ghadiri, F. Dessauge et al., "Modulating apoptosis as a target for effective therapy," Molecular Immunology, vol. 43, no. 8, pp. 1065-1079, 2006.

[22] N. Okada, A. Hirata, Y. Murakami, M. Shoji, H. Sakagami, and S. Fujisawa, "Induction of cytotoxicity and apoptosis and inhibition of cyclooxygenase-2 gene expression by eugenol-related compounds," Anticancer Research, vol. 25, no. 5, pp. 3263-3269, 2005.

[23] J.-L. Yi, S. Shi, Y. L. Shen et al., "Myricetin and methyl eugenol combination enhances the anticancer activity, cell cycle 
arrest and apoptosis induction of cis-platin against HeLa cervical cancer cell lines," International Journal of Clinical and Experimental Pathology, vol. 8, no. 2, pp. 1116-1127, 2015.

[24] A. Gemma, K. Takenaka, Y. Hosoya et al., "Altered expression of several genes in highly metastatic subpopulations of a human pulmonary adenocarcinoma cell line," European Journal of Cancer, vol. 37, no. 12, pp. 1554-1561, 2001.

[25] F. H. Sarkar and Y. Li, "Using chemopreventive agents to enhance the efficacy of cancer therapy," Cancer Research, vol. 66, no. 7, pp. 3347-3350, 2006.

[26] D. R. Youlden, S. M. Cramb, C. H. Yip, and P. D. Baade, "Incidence and mortality of female breast cancer in the Asia-Pacific region," Cancer Biology \& Medicine, vol. 11, no. 2, pp. 101-115, 2014.

[27] N. Vidhya and S. N. Devaraj, "Induction of apoptosis by eugenol in human breast cancer cells," Indian Journal of Experimental Biology, vol. 49, no. 11, pp. 871-878, 2011.

[28] M. Pisano, G. Pagnan, M. Loi et al., "Antiproliferative and proapoptotic activity of eugenol-related biphenyls on malignant melanoma cells," Molecular Cancer, vol. 6, no. 1, p. 8, 2007.

[29] S. Kachhap, A. Pratap, and D. S. Toppo, "Abdominal malignant melanoma: rare case report," International Journal of Scientific Research, vol. 8, no. 9, 2019.

[30] A. J. Miller and M. C. Mihm Jr., "Melanoma," New England Journal of Medicine, vol. 355, no. 1, pp. 51-65, 2006.

[31] M. Miyazawa and M. Hisama, "Suppression of chemical mutagen-induced SOS response by alkylphenols from clove (Syzygium aromaticum) in the Salmonella typhimurium TA1535/pSK1002 umu test," Journal of Agricultural and Food Chemistry, vol. 49, no. 8, pp. 4019-4025, 2001.

[32] G. C. Kim, D. S. Choi, J. S. Lim et al., "Caspases-dependent apoptosis in human melanoma cell by eugenol," The Korean Journal of Anatomy, vol. 39, no. 3, pp. 245-253, 2006.

[33] R. Ghosh, N. Nadiminty, J. E. Fitzpatrick, W. L. Alworth, T. J. Slaga, and A. P. Kumar, "Eugenol Causes Melanoma Growth Suppression through Inhibition of E2F1 Transcriptional Activity," Journal of Biological Chemistry, vol. 280, no. 7, pp. 5812-5819, 2005.

[34] D. M. Parkin, F. Bray, J. Ferlay, and P. Pisani, "Global cancer statistics, 2002,” CA: a Cancer Journal for Clinicians, vol. 55, no. 2, pp. 74-108, 2005.

[35] E. F. Dunne and I. U. Park, "HPV and HPV-associated diseases," Infectious Disease Clinics, vol. 27, no. 4, pp. 765-778, 2013.

[36] C. M. Tarney and J. Han, "Postcoital bleeding: a review on etiology, diagnosis, and management," Obstetrics and Gynecology International, vol. 2014, Article ID 192087, 8 pages, 2014.

[37] İ. Gülcin, "Antioxidant and antiradical activities of L-carnitine," Life Sciences, vol. 78, no. 8, pp. 803-811, 2006.

[38] I. Gülçin, E. Bursal, M. H. Şehitoğlu, M. Bilsel, and A. C. Gören, "Polyphenol contents and antioxidant activity of lyophilized aqueous extract of propolis from Erzurum, Turkey," Food and Chemical Toxicology, vol. 48, no. 8-9, pp. 2227-2238, 2010.

[39] G. Anuj and S. Sanjay, "Eugenol: a potential phytochemical with multifaceted therapeutic activities," Pharmacology, vol. 2, pp. 108-120, 2010.

[40] İ. Gülçin, "Antioxidant activity of eugenol: a structure-activity relationship study," Journal of Medicinal Food, vol. 14, no. 9, pp. 975-985, 2011.
[41] S.-W. Huang and E. N. Frankel, "Antioxidant activity of tea catechins in different lipid systems," Journal of Agricultural and Food Chemistry, vol. 45, no. 8, pp. 3033-3038, 1997.

[42] H. Sies, Oxidative Stress: Oxidants and Antioxidants, Academic Press, New York, 1991.

[43] T. Atsumi, S. Fujisawa, and K. Tonosaki, "A comparative study of the antioxidant/prooxidant activities of eugenol and isoeugenol with various concentrations and oxidation conditions," Toxicology In Vitro, vol. 19, no. 8, pp. 1025-1033, 2005.

[44] D. P. Bezerra, G. Militão, M. de Morais, and D. de Sousa, "The dual antioxidant/prooxidant effect of eugenol and its action in cancer development and treatment," Nutrients, vol. 9, no. 12, p. 1367, 2017.

[45] M. OGATA, M. HOSHI, S. URANO, and T. ENDO, "Antioxidant activity of eugenol and related monomeric and dimeric compounds," Chemical and Pharmaceutical Bulletin, vol. 48, no. 10, pp. 1467-1469, 2000.

[46] E. Nagababu and N. Lakshmaiah, "Inhibition of microsomal lipid peroxidation and monooxygenase activities by eugenol," Free Radical Research, vol. 20, no. 4, pp. 253-266, 1994.

[47] K.-G. Lee and T. Shibamoto, “Antioxidant property of aroma extract isolated from clove buds [Syzygium aromaticum (L.) Merr. et Perry]," Food Chemistry, vol. 74, no. 4, pp. 443448, 2001.

[48] H. Nam and M.-M. Kim, "Eugenol with antioxidant activity inhibits MMP-9 related to metastasis in human fibrosarcoma cells," Food and Chemical Toxicology, vol. 55, pp. 106-112, 2013.

[49] S. Fujisawa, T. Atsumi, Y. Kadoma, and H. Sakagami, "Antioxidant and prooxidant action of eugenol-related compounds and their cytotoxicity," Toxicology, vol. 177, no. 1, pp. 39-54, 2002.

[50] J. Chogo and G. Crank, "Chemical composition and biological activity of the Tanzanian plant Ocimum suave," Journal of Natural Products, vol. 44, no. 3, pp. 308-311, 1981.

[51] M. Asha, D. Prashanth, B. Murali, R. Padmaja, and A. Amit, "Anthelmintic activity of essential oil of_Ocimum sanctum_ and eugenol," Fitoterapia, vol. 72, no. 6, pp. 669-670, 2001.

[52] J. N. Barboza, C. da Silva Maia Bezerra Filho, R. O. Silva, J. V. R. Medeiros, and D. P. de Sousa, "An overview on the antiinflammatory potential and antioxidant profile of eugenol," Oxidative Medicine and Cellular Longevity, vol. 2018, Article ID 3957262, 9 pages, 2018.

[53] M. A. Morsy and A. A. Fouad, "Mechanisms of gastroprotective effect of eugenol in indomethacin-induced ulcer in rats," Phytotherapy Research: An International Journal Devoted to Pharmacological and Toxicological Evaluation of Natural Product Derivatives, vol. 22, no. 10, pp. 1361-1366, 2008.

[54] S. Jain, R. R. Kulkarni, and D. P. Jain, "Current drug targets for antihyperlipidemic therapy," Mini Reviews in Medicinal Chemistry, vol. 10, no. 3, pp. 232-262, 2010.

[55] Å. L. Amundsen, L. Ose, M. S. Nenseter, and F. Y. Ntanios, "Plant sterol ester-enriched spread lowers plasma total and LDL cholesterol in children with familial hypercholesterolemia," The American Journal of Clinical Nutrition, vol. 76, no. 2, pp. 338-344, 2002.

[56] T. Ichihashi, M. Izawa, K. Miyata, T. Mizui, K. Hirano, and Y. Takagishi, "Mechanism of hypocholesterolemic action of S-8921 in rats: S-8921 inhibits ileal bile acid absorption," Journal of Pharmacology and Experimental Therapeutics, vol. 284, no. 1, pp. 43-50, 1998. 
[57] W. Shi, M. E. Haberland, M. L. Jien, D. M. Shih, and A. J. Lusis, "Endothelial responses to oxidized lipoproteins determine genetic susceptibility to atherosclerosis in mice," Circulation, vol. 102, no. 1, pp. 75-81, 2000.

[58] E. Hopps, D. Noto, G. Caimi, and M. R. Averna, "A novel component of the metabolic syndrome: the oxidative stress," Nutrition, Metabolism and Cardiovascular Diseases, vol. 20, no. 1, pp. 72-77, 2010.

[59] M. M. Duarte, J. B. T. Rocha, R. N. Moresco et al., "Association between ischemia-modified albumin, lipids and inflammation biomarkers in patients with hypercholesterolemia," Clinical Biochemistry, vol. 42, no. 7-8, pp. 666-671, 2009.

[60] K. Srinivasan, "Antioxidant potential of spices and their active constituents," Critical Reviews in Food Science and Nutrition, vol. 54, no. 3, pp. 352-372, 2014.

[61] K. Venkadeswaran, A. R. Muralidharan, T. Annadurai et al., "Antihypercholesterolemic and antioxidative potential of an extract of the plant, Piper betle, and its active constituent, eugenol, in triton WR-1339-induced hypercholesterolemia in experimental rats," Evidence-based Complementary and Alternative Medicine, vol. 2014, Article ID 478973, 11 pages, 2014.

[62] L. F. L. Interaminense, D. M. Jucá, P. J. C. Magalhães, J. H. Leal-Cardoso, G. P. Duarte, and S. Lahlou, "Pharmacological evidence of calcium-channel blockade by essential oil of Ocimum gratissimum and its main constituent, eugenol, in isolated aortic rings from DOCA-salt hypertensive rats," Fundamental \& Clinical Pharmacology, vol. 21, no. 5, pp. 497-506, 2007.

[63] C. E. N. Damiani, L. V. Rossoni, and D. V. Vassallo, "Vasorelaxant effects of eugenol on rat thoracic aorta," Vascular Pharmacology, vol. 40, no. 1, pp. 59-66, 2003.

[64] S. Jin and K.-H. Cho, "Water extracts of cinnamon and clove exhibits potent inhibition of protein glycation and antiatherosclerotic activity in vitro and in vivo hypolipidemic activity in zebrafish," Food and Chemical Toxicology, vol. 49, no. 7, pp. 1521-1529, 2011.

[65] A. Munisa and J. D. Parangtambung, "The effect of clove leaf methanol extract on the profiles of superoxide dismutase and malondialdehyde in the liver of rabbits under hypercholesterolemia condition," Translational Biomedicine, vol. 6, no. 2, pp. 1-5, 2015.

[66] O. Sensch, W. Vierling, W. Brandt, and M. Reiter, "Effects of inhibition of calcium and potassium currents in guinea-pig cardiac contraction: comparison of $\beta$-caryophyllene oxide, eugenol, and nifedipine," British Journal of Pharmacology, vol. 131, no. 6, pp. 1089-1096, 2000.

[67] R. Choudhary, K. Mishra, and C. Subramanyam, "Prevention of isoproterenol-induced cardiac hypertrophy by eugenol, an antioxidant," Indian Journal of Clinical Biochemistry, vol. 21, no. 2, p. 107, 2006.

[68] H. U. Tahir, R. A. Sarfraz, A. Ashraf, and S. Adil, "Chemical composition and antidiabetic activity of essential oils obtained from two spices (Syzygium aromaticumandCuminum cyminum)," International Journal of Food Properties, vol. 19, no. 10, pp. 2156-2164, 2016.

[69] H. Genç Bilgiçli, A. Kestane, P. Taslimi et al., "Novel eugenol bearing oxypropanolamines: synthesis, characterization, antibacterial, antidiabetic, and anticholinergic potentials," Bioorganic Chemistry, vol. 88, p. 102931, 2019.

[70] S. Srinivasan, G. Sathish, M. Jayanthi, J. Muthukumaran, U. Muruganathan, and V. Ramachandran, "Ameliorating effect of eugenol on hyperglycemia by attenuating the key enzymes of glucose metabolism in streptozotocin-induced diabetic rats," Molecular and Cellular Biochemistry, vol. 385, no. 1-2, pp. 159-168, 2014.

[71] S. Hirst and L. Stapley, "Parasitology: the dawn of a new millennium," Parasitology Today, vol. 16, no. 1, pp. 1-3, 2000.

[72] A. M. el-kady, A. A. Ahmad, T. M. Hassan, H. E. M. el-Deek, S. S. Fouad, and S. S. al-Thaqfan, " $<\mathrm{p}>$ Eugenol, a potential schistosomicidal agent with anti-inflammatory and antifibrotic effects against $<$ em $>$ Schistosoma mansoni $</$ em $>$, induced liver pathology $</ \mathrm{p}\rangle$," Infection and drug resistance, vol. Volume 12, pp. 709-719, 2019.

[73] D. G. Colley, A. L. Bustinduy, W. E. Secor, and C. H. King, "Human schistosomiasis," The Lancet, vol. 383, no. 9936, pp. 2253-2264, 2014.

[74] E. Quansah, E. Sarpong, and T. K. Karikari, "Disregard of neurological impairments associated with neglected tropical diseases in Africa," Eneurologicalsci, vol. 3, pp. 11-14, 2016.

[75] T. Vos, A. D. Flaxman, M. Naghavi et al., "Years lived with disability (YLDs) for 1160 sequelae of 289 diseases and injuries 1990-2010: a systematic analysis for the Global Burden of Disease Study 2010," The Lancet, vol. 380, no. 9859, pp. 2163-2196, 2012.

[76] D. M. Metwally, E. M. al-Olayan, M. Alanazi, S. B. Alzahrany, and A. Semlali, "Antischistosomal and anti-inflammatory activity of garlic and allicin compared with that of praziquantel in vivo," BMC Complementary and Alternative Medicine, vol. 18, no. 1, p. 135, 2018.

[77] H. Kato, E. Gomez, A. Cáceres, H. Uezato, T. Mimori, and Y. Hashiguchi, "Molecular epidemiology for vector research on leishmaniasis," International Journal of Environmental Research and Public Health, vol. 7, no. 3, pp. 814-826, 2010.

[78] R. R. Mendonça-Filho, I. A. Rodrigues, D. S. Alviano et al., "Leishmanicidal activity of polyphenolic-rich extract from husk fiber of _Cocos nucifera_Linn. (Palmae)," Research in Microbiology, vol. 155, no. 3, pp. 136-143, 2004.

[79] T. Ueda-Nakamura, R. R. Mendonça-Filho, J. A. MorgadoDíaz et al., "Antileishmanial activity of Eugenol-rich essential oil from _Ocimum gratissimum_" Parasitology International, vol. 55, no. 2, pp. 99-105, 2006.

[80] E. Scallan, P. M. Griffin, F. J. Angulo, R. V. Tauxe, and R. M. Hoekstra, "Foodborne illness acquired in the United States-unspecified agents," Emerging Infectious Diseases, vol. 17, no. 1, pp. 16-22, 2011.

[81] K. P. Devi, S. A. Nisha, R. Sakthivel, and S. K. Pandian, "Eugenol (an essential oil of clove) acts as an antibacterial agent against_Salmonella typhi_by disrupting the cellular membrane," Journal of Ethnopharmacology, vol. 130, no. 1, pp. 107-115, 2010.

[82] M. Hyldgaard, T. Mygind, and R. L. Meyer, "Essential oils in food preservation: mode of action, synergies, and interactions with food matrix components," Frontiers in Microbiology, vol. 3, p. 12, 2012.

[83] A. Marchese, R. Barbieri, E. Coppo et al., "Antimicrobial activity of eugenol and essential oils containing eugenol: a mechanistic viewpoint," Critical Reviews in Microbiology, vol. 43, no. 6, pp. 668-689, 2017.

[84] F. Nazzaro, F. Fratianni, L. de Martino, R. Coppola, and V. de Feo, "Effect of essential oils on pathogenic bacteria," Pharmaceuticals, vol. 6, no. 12, pp. 1451-1474, 2013. 
[85] A. Gill and R. Holley, "Disruption of Escherichia coli, Listeria monocytogenes and Lactobacillus sakei cellular membranes by plant oil aromatics," International Journal of Food Microbiology, vol. 108, no. 1, pp. 1-9, 2006.

[86] C. T. Filgueiras and M. C. D. Vanetti, "Effect of eugenol on growth and listeriolysin $\mathrm{O}$ production by Listeria monocytogenes," Brazilian Archives of Biology and Technology, vol. 49, no. 3, pp. 405-409, 2006.

[87] D. Trombetta, F. Castelli, M. G. Sarpietro et al., "Mechanisms of antibacterial action of three monoterpenes," Antimicrobial Agents and Chemotherapy, vol. 49, no. 6, pp. 2474-2478, 2005.

[88] A. A. Catherine, H. Deepika, and P. S. Negi, "Antibacterial activity of eugenol and peppermint oil in model food systems," Journal of Essential Oil Research, vol. 24, no. 5, pp. 481-486, 2012.

[89] M. M. Iwu, "African medicinal plants in the search for new drugs based on ethnobotanical leads," in Ciba Foundation Symposium 185-Ethnobotany and the Search for New Drugs: Ethnobotany and the Search for New Drugs: Ciba Foundation Symposium 185, John Wiley \& Sons, Ltd, Chichester, UK, 2007.

[90] S. Hemaiswarya and M. Doble, "Synergistic interaction of eugenol with antibiotics against Gram negative bacteria," Phytomedicine, vol. 16, no. 11, pp. 997-1005, 2009.

[91] S.-E. Moon, H.-Y. Kim, and J.-D. Cha, "Synergistic effect between clove oil and its major compounds and antibiotics against oral bacteria," Archives of Oral Biology, vol. 56, no. 9, pp. 907-916, 2011.

[92] G. Straface, A. Selmin, V. Zanardo, M. de Santis, A. Ercoli, and G. Scambia, "Herpes simplex virus infection in pregnancy," Infectious Diseases in Obstetrics and Gynecology, vol. 2012, Article ID 385697, 6 pages, 2012.

[93] F. Benencia and M. Courreges, "In vitro and in vivo activity of eugenol on human herpesvirus," Phytotherapy Research: An International Journal Devoted to Pharmacological and Toxicological Evaluation of Natural Product Derivatives, vol. 14, no. 7, pp. 495-500, 2000.

[94] A. Astani, J. Reichling, and P. Schnitzler, "Screening for antiviral activities of isolated compounds from essential oils," Evidence-based Complementary and Alternative Medicine, vol. 2011, Article ID nep187, 8 pages, 2011.

[95] A. T. Palamara, C. F. Perno, M. R. Ciriolo et al., "Evidence for antiviral activity of glutathione: in vitro inhibition of herpes simplex virus type 1 replication," Antiviral Research, vol. 27, no. 3, pp. 237-253, 1995.

[96] J. Serkedjieva and N. Manolova, "Plant polyphenolic complex inhibits the reproduction of influenza and herpes simplex viruses," in Plant Polyphenols, pp. 705-715, Springer, 1992.

[97] Y. Tragoolpua and A. Jatisatienr, "Anti-herpes simplex virus activities of Eugenia caryophyllus (Spreng.) Bullock \& SG Harrison and essential oil, eugenol," Phytotherapy Research: An International Journal Devoted to Pharmacological and Toxicological Evaluation of Natural Product Derivatives, vol. 21, no. 12, pp. 1153-1158, 2007.

[98] J. Serkedjieva and S. Ivancheva, "Antiherpes virus activity of extracts from the medicinal plant Geranium sanguineum L," Journal of Ethnopharmacology, vol. 64, no. 1, pp. 59-68, 1998.

[99] A. A. Barquero, L. E. Alché, and C. E. Coto, "Antiviral activity of meliacine on the replication of a thymidine kinase- deficient mutant of herpes simplex virus type 1 alone and in combination with acyclovir," International Journal of Antimicrobial Agents, vol. 9, no. 1, pp. 49-55, 1997.

[100] M. Kurokawa, K. Nagasaka, T. Hirabayashi et al., "Efficacy of traditional herbal medicines in combination with acyclovir against herpes simplex virus type 1 infection in vitro and in vivo," Antiviral Research, vol. 27, no. 1-2, pp. 19-37, 1995.

[101] M. N. Prichard and C. Shipman Jr., "A three-dimensional model to analyze drug-drug interactions," Antiviral Research, vol. 14, no. 4-5, pp. 181-205, 1990.

[102] G. B. Zore, A. D. Thakre, S. Jadhav, and S. M. Karuppayil, "Terpenoids inhibit_Candida albicans_growth by affecting membrane integrity and arrest of cell cycle," Phytomedicine, vol. 18, no. 13, pp. 1181-1190, 2011.

[103] C. Wang, J. Zhang, H. Chen, Y. Fan, and Z. Shi, “Antifungal activity of eugenol against Botrytis cinerea," Tropical Plant Pathology, vol. 35, no. 3, pp. 137-143, 2010.

[104] J. Sikkema, J. A. de Bont, and B. Poolman, "Mechanisms of membrane toxicity of hydrocarbons," Microbiological Reviews, vol. 59, no. 2, pp. 201-222, 1995.

[105] A. Ahmad, A. Khan, L. A. Khan, and N. Manzoor, "In vitro synergy of eugenol and methyleugenol with fluconazole against clinical Candida isolates," Journal of Medical Microbiology, vol. 59, no. 10, pp. 1178-1184, 2010.

[106] R. Medzhitov, "Origin and physiological roles of inflammation," Nature, vol. 454, no. 7203, pp. 428-435, 2008.

[107] L. Ferrero-Miliani, O. H. Nielsen, P. S. Andersen, and S. E. Girardin, "Chronic inflammation: importance of NOD2 and NALP3 in interleukin-1beta generation," Clinical \& Experimental Immunology, vol. 147, no. 2, pp. 227-235, 2007.

[108] R. A. Saraiva, M. K. A. Araruna, R. C. Oliveira et al., “Topical anti-inflammatory effect of _Caryocar coriaceum_ Wittm. (Caryocaraceae) fruit pulp fixed oil on mice ear edema induced by different irritant agents," Journal of Ethnopharmacology, vol. 136, no. 3, pp. 504-510, 2011.

[109] A. Ayala, M. F. Muñoz, and S. Argüelles, "Lipid peroxidation: production, metabolism, and signaling mechanisms of malondialdehyde and 4-hydroxy-2-nonenal," Oxidative Medicine and Cellular Longevity, vol. 2014, Article ID 360438, 31 pages, 2014.

[110] S. K. Biswas, J. B. Lopes, and D. Faria, "Which comes first: renal inflammation or oxidative stress in spontaneously hypertensive rats?," Free Radical Research, vol. 41, no. 2, pp. 216-224, 2007.

[111] C. B. Magalhães, D. R. Riva, L. J. DePaula et al., "In vivo antiinflammatory action of eugenol on lipopolysaccharideinduced lung injury," Journal of Applied Physiology, vol. 108, no. 4, pp. 845-851, 2010.

[112] X. Huang, Y. Liu, Y. Lu, and C. Ma, "Anti-inflammatory effects of eugenol on lipopolysaccharide-induced inflammatory reaction in acute lung injury via regulating inflammation and redox status," International Immunopharmacology, vol. 26, no. 1, pp. 265-271, 2015.

[113] P. Patlevič, J. Vašková, P. Švorc Jr., L. Vaško, and P. Švorc, "Reactive oxygen species and antioxidant defense in human gastrointestinal diseases," Integrative medicine research, vol. 5, no. 4, pp. 250-258, 2016.

[114] J. Feng and J. Lipton, "Eugenol: antipyretic activity in rabbits,” Neuropharmacology, vol. 26, no. 12, pp. 1775-1778, 1987. 
[115] P. Brodin and A. Røed, "Effects of eugenol on rat phrenic nerve and phrenic nerve-diaphragm preparations," Archives of Oral Biology, vol. 29, no. 8, pp. 611-615, 1984.

[116] W. Hume, "Effect of eugenol on constrictor responses in blood vessels of the rabbit ear," Journal of Dental Research, vol. 62, no. 9, pp. 1013-1015, 1983.

[117] F. Dewhirst and J. Goodson, "Prostaglandin synthetase inhibition by eugenol, guaiacol and other dental medicaments," in Journal of Dental Research, vol. 53, p. 104, American Association for Dental Research, Alexandria, VA, USA, 1974.

[118] K. Markowitz, M. Moynihan, M. Liu, and S. Kim, "Biologic properties of eugenol and zinc oxide-eugenol: a clinically oriented review," Oral Surgery, Oral Medicine, Oral Pathology, vol. 73, no. 6, pp. 729-737, 1992.

[119] G. Chung, J. N. Rhee, S. J. Jung, J. S. Kim, and S. B. Oh, "Modulation of CaV2. 3 calcium channel currents by eugenol," Journal of Dental Research, vol. 87, no. 2, pp. 137141, 2008.

[120] C.-K. Park, H. Y. Li, K. Y. Yeon et al., "Eugenol inhibits sodium currents in dental afferent neurons," Journal of Dental Research, vol. 85, no. 10, pp. 900-904, 2006.

[121] S.-J. Lee, J. I. Han, G. S. Lee et al., “Antifungal effect of eugenol and nerolidol against Microsporum gypseum in a guinea pig model," Biological and Pharmaceutical Bulletin, vol. 30, no. 1, pp. 184-188, 2007.

[122] M. Inoue, T. Fujita, M. Goto, and E. Kumamoto, "Presynaptic enhancement by eugenol of spontaneous excitatory transmission in rat spinal substantia gelatinosa neurons is mediated by transient receptor potential A1 channels," Neuroscience, vol. 210, pp. 403-415, 2012.

[123] H. Aoshima and K. Hamamoto, "Potentiation of GABAA receptors expressed in Xenopus oocytes by perfume and phytoncid," Bioscience, Biotechnology, and Biochemistry, vol. 63, no. 4, pp. 743-748, 1999.

[124] B. Yang, Z. G. Piao, Y. B. Kim et al., "Activation of vanilloid receptor 1 (VR1) by eugenol," Journal of Dental Research, vol. 82, no. 10, pp. 781-785, 2003.

[125] C.-K. Park, K. Kim, S. J. Jung et al., "Molecular mechanism for local anesthetic action of eugenol in the rat trigeminal system," PAIN, vol. 144, no. 1, pp. 84-94, 2009.

[126] C. E. Ferland, F. Beaudry, and P. Vachon, "Antinociceptive effects of eugenol evaluated in a monoiodoacetate-induced osteoarthritis rat model," Phytotherapy Research, vol. 26, no. 9, pp. 1278-1285, 2012.

[127] A. N. Daniel, S. M. Sartoretto, G. Schmidt, S. M. CaparrozAssef, C. A. Bersani-Amado, and R. K. N. Cuman, "Antiinflammatory and antinociceptive activities A of eugenol essential oil in experimental animal models," Revista Brasileira de Farmacognosia, vol. 19, no. 1B, pp. 212-217, 2009.

[128] S. L. Bodhankar, R. Kurian, D. K. Arulmozhi, and A. Veeranjaneyulu, "Effect of eugenol on animal models of nociception," Indian Journal of Pharmacology, vol. 38, no. 5, p. 341, 2006.

[129] Y. Irie, "Effects of eugenol on the central nervous system: its possible application to treatment of Alzheimer's disease, depression, and Parkinson's disease," Current Bioactive Compounds, vol. 2, no. 1, pp. 57-66, 2006.

[130] Y. Irie and W. M. Keung, "Rhizoma acori graminei and its active principles protect PC-12 cells from the toxic effect of amyloid- $\beta$ peptide," Brain Research, vol. 963, no. 1-2, pp. 282-289, 2003.
[131] G. Bupesh, K. Meenakumari, J. Prabhu et al., "Molecular properties and insilico neuroprotective activity of eugenol against glutamate metabotrophic receptors," International Journal of Pharmaceutical Sciences Review \& Research, vol. 40, no. 1, pp. 318-323, 2016.

[132] H. Kabuto, M. Tada, and M. Kohno, "Eugenol [2-methoxy-4(2-propenyl) phenol] prevents 6-hydroxydopamine-induced dopamine depression and lipid peroxidation inductivity in mouse striatum," Biological and Pharmaceutical Bulletin, vol. 30, no. 3, pp. 423-427, 2007.

[133] M. Müller, H. C. Pape, E. J. Speckmann, and A. Gorji, “Effect of eugenol on spreading depression and epileptiform discharges in rat neocortical and hippocampal tissues," Neuroscience, vol. 140, no. 2, pp. 743-751, 2006.

[134] P. Sen, P. C. Maiti, S. Puri, A. Ray, N. A. Audulov, and A. V. Valdman, "Mechanism of anti-stress activity of Ocimum sanctum Linn, eugenol and Tinospora malabarica in experimental animals," Indian Journal of Experimental Biology, vol. 30, no. 7, pp. 592-596, 1992.

[135] K. Yazaki, "Study of behavioral pharmacology on rats. Tranquilizing effects induced by endogenous or exogenous bradykinin. Shika gakuho," Dental Science Reports, vol. 89, no. 10, pp. 1529-1548, 1989.

[136] D. Garabadu, A. Shah, A. Ahmad et al., "Eugenol as an antistress agent: modulation of hypothalamic-pituitary-adrenal axis and brain monoaminergic systems in a rat model of stress," Stress, vol. 14, no. 2, pp. 145-155, 2011.

[137] D. Garabadu, A. Shah, S. Singh, and S. Krishnamurthy, "Protective effect of eugenol against restraint stress-induced gastrointestinal dysfunction: potential use in irritable bowel syndrome," Pharmaceutical Biology, vol. 53, no. 7, pp. 968974, 2015.

[138] S. N. Prasad, "Neuroprotective efficacy of eugenol and isoeugenol in acrylamide-induced neuropathy in rats: behavioral and biochemical evidence," Neurochemical Research, vol. 38, no. 2, pp. 330-345, 2013.

[139] P. Srivastava and R. S. Yadav, "Efficacy of natural compounds in neurodegenerative disorders," in The Benefits of Natural Products for Neurodegenerative Diseases, pp. 107-123, Springer, 2016.

[140] M. Wahid, A. Ali, F. Saqib et al., "Pharmacological exploration of traditional plants for the treatment of neurodegenerative disorders," Phytotherapy research, vol. 34, no. 12, pp. 3089-3112, 2020.

[141] D. C. Rubinsztein, "The roles of intracellular proteindegradation pathways in neurodegeneration," Nature, vol. 443, no. 7113, pp. 780-786, 2006.

[142] P. F. C. Lim, X. Y. Liu, L. Kang, P. C. L. Ho, Y. W. Chan, and S. Y. Chan, "Limonene GP1/PG organogel as a vehicle in transdermal delivery of haloperidol," International Journal of Pharmaceutics, vol. 311, no. 1-2, pp. 157-164, 2006.

[143] R. Jeevan, R. Venkat, M. A. Khan et al., "Effect of menthol and related terpenes on the percutaneous absorption of propranolol across excised hairless mouse skin," Journal of Pharmaceutical Sciences, vol. 86, no. 12, pp. 1369-1373, 1997.

[144] Q. Shen, W. Li, and W. Li, "The effect of clove oil on the transdermal delivery of ibuprofen in the rabbit by in vitro and in vivo methods," Drug Development and Industrial Pharmacy, vol. 33, no. 12, pp. 1369-1374, 2007.

[145] M. H. Medeiros, P. Dimascio, A. P. Pinto, R. R. Vargas, and E. J. H. Bechara, "Horseradish peroxidase-catalyzed 
conjugation of eugenol with basic amino acids," Free Radical Research, vol. 25, no. 1, pp. 5-12, 1996.

[146] H. Someya, Y. Higo, M. Ohno, T. W. Tsutsui, and T. Tsutsui, "Clastogenic activity of seven endodontic medications used in dental practice in human dental pulp cells," Mutation Research/Genetic Toxicology and Environmental Mutagenesis, vol. 650, no. 1, pp. 39-47, 2008.

[147] R. Gerosa, M. Borin, G. Menegazzi, M. Puttini, and G. Cavalleri, "In vitro evaluation of the cytotoxicity of pure eugenol," Journal of Endodontics, vol. 22, no. 10, pp. 532534, 1996.

[148] S. P. Brinker, "Provisional excellence with zinc-oxide noneugenol temporary cement," Provider, vol. 501, p. 355110, 2014.

[149] S. A. GUENETTE, F. BEAUDRY, J. F. MARIER, and P. VACHON, "Pharmacokinetics and anesthetic activity of eugenol in male Sprague-Dawley rats," Journal of Veterinary Pharmacology and Therapeutics, vol. 29, no. 4, pp. 265-270, 2006.

[150] S. A. Tajuddin, A. Latif, and I. A. Qasmi, “Aphrodisiac activity of $50 \%$ ethanolic extracts of Myristica fragrans Houtt.(nutmeg) and Syzygium aromaticum (L) Merr. \& Perry.(clove) in male mice: a comparative study," $B M C$ Complementary and Alternative Medicine, vol. 3, p. 6, 2003.

[151] R. Capasso, L. Pinto, M. L. Vuotto, and G. di Carlo, "Preventive effect of eugenol on PAF and ethanol-induced gastric mucosal damage," Fitoterapia, vol. 71, pp. S131-S137, 2000.

[152] A. Bennett, I. F. Stamford, I. A. Tavares et al., "The biological activity of eugenol, a major constituent of nutmeg (Myristica fragrans): studies on prostaglandins, the intestine and other tissues," Phytotherapy Research, vol. 2, no. 3, pp. 124-130, 1988.

[153] S. Karmakar, M. Choudhury, A. S. Das, A. Maiti, S. Majumdar, and C. Mitra, "Clove (Syzygium aromaticum Linn) extract rich in eugenol and eugenol derivatives shows bone-preserving efficacy," Natural Product Research, vol. 26, no. 6, pp. 500-509, 2012. 